
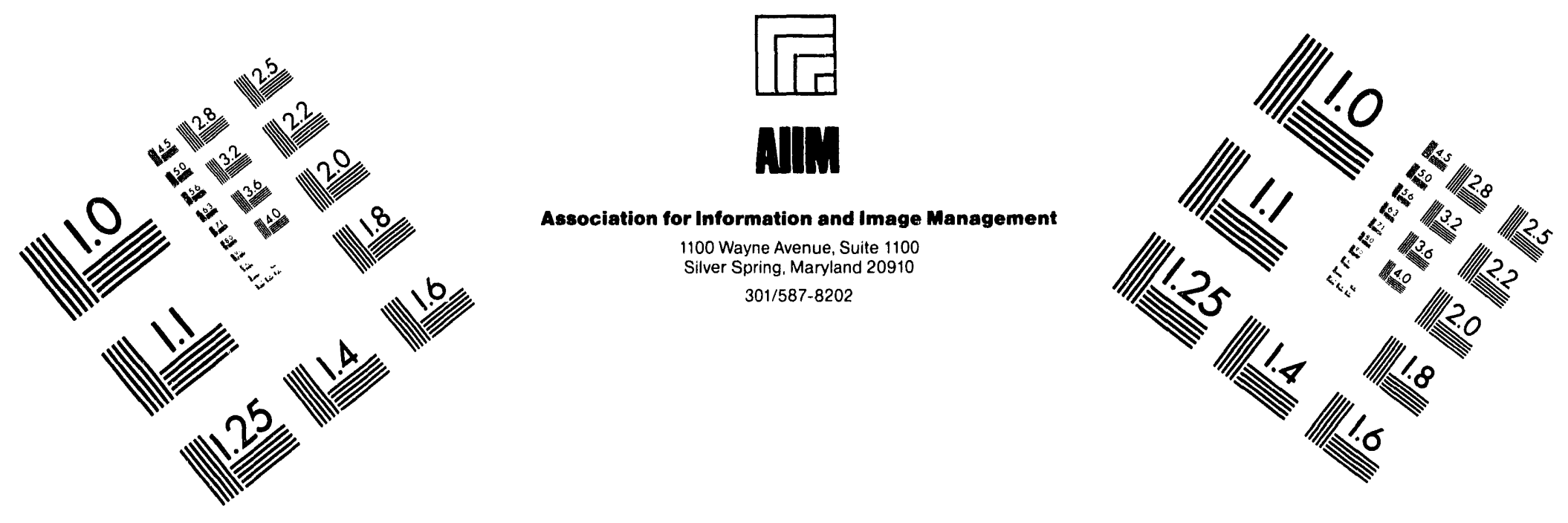

\title{
Centimeter
}

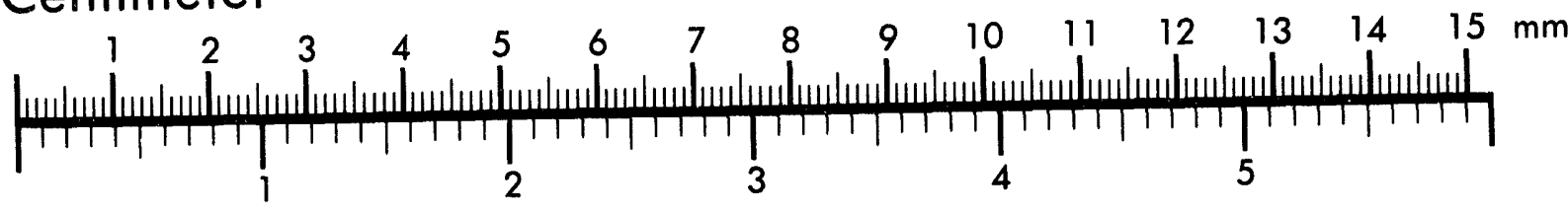
Inches
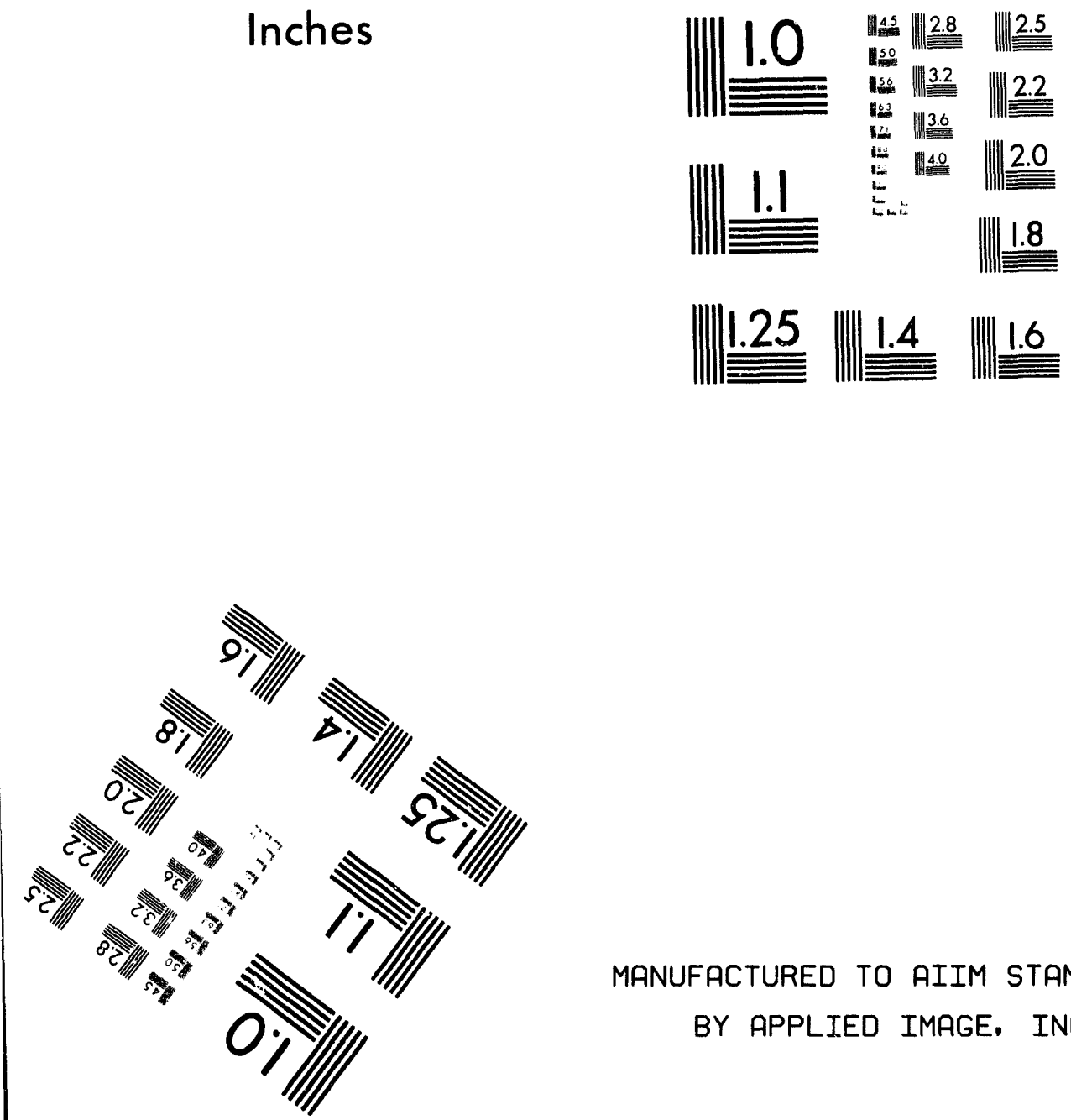

MANUFACTURED TO AIIM STANDARDS BY APPLIED IMAGE, INC.

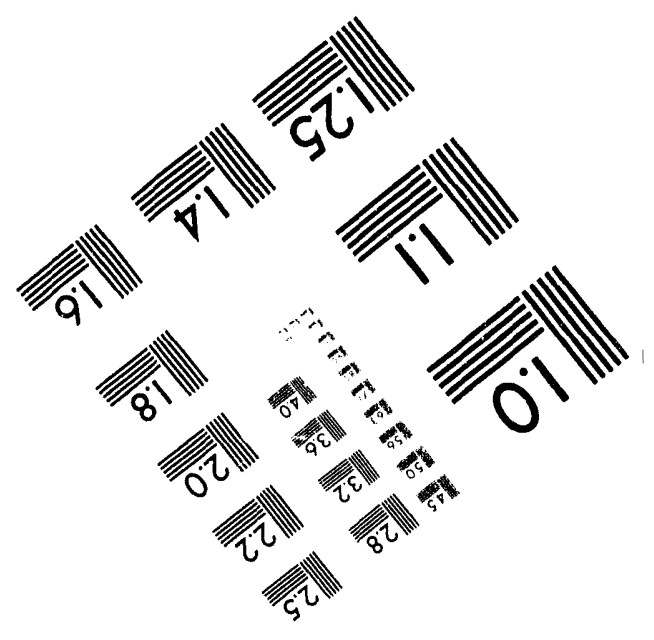



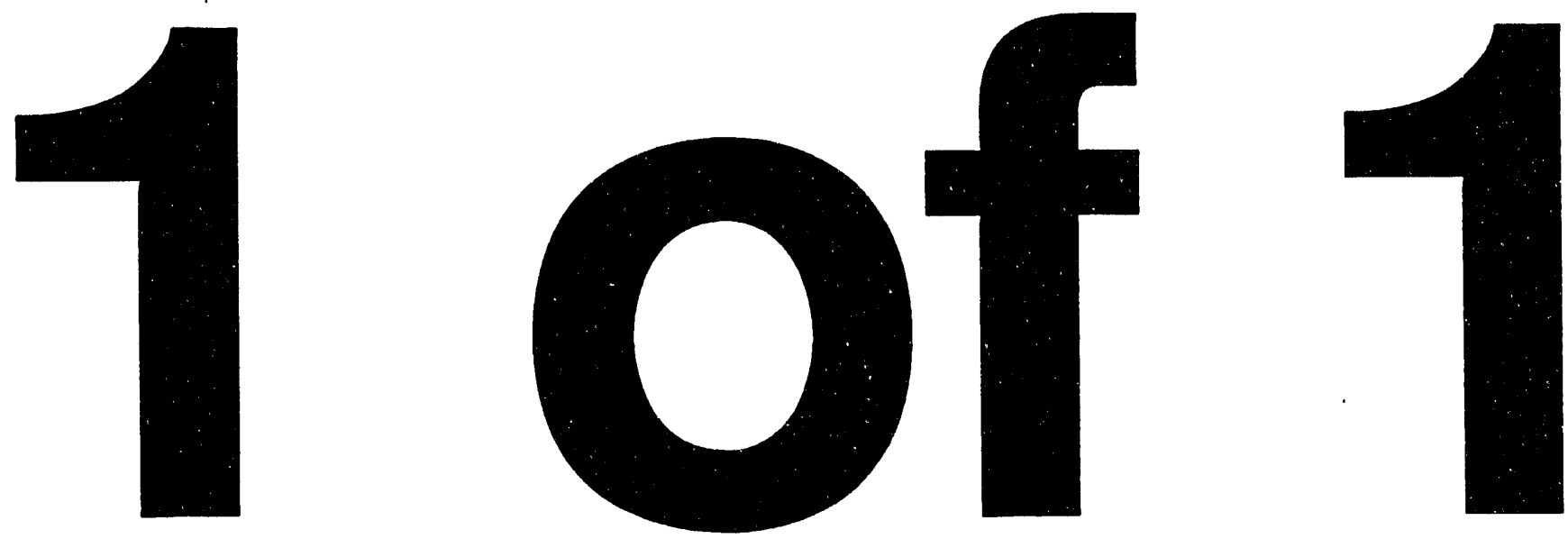


\section{HW- 83569}

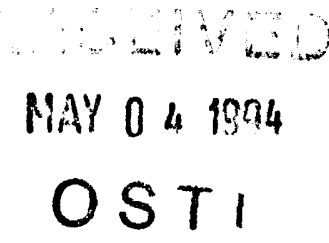

Cover Sheet for a Hanford

Historical Document

Released for Public Availability

Released 1994

Prepared for the U.S. Department of Energy under Contract DE-AC06-76RLO 1830

Pacific Northwest Laboratory

Operated for the U.S. Department of Energy by Battelle Memorial Institute 


\section{DISClAIMER}

This is a historical document that is being released for public availability. This was made from the best available copy. Neither the United States Government nor any agency thereof, nor Battelle Memorial Institute, nor any of their employer's, makes any warranty, express or implied, or assumes any legal liability or responsibility for the accuracy, completeness, or usefulness of any information, apparatus, product, or process disclosed, or represents that its use would not infringe privately owned rights. The views and opinions of authors expressed herein do not necessarily state or reflect those of the United States Government or any agency thereof. 


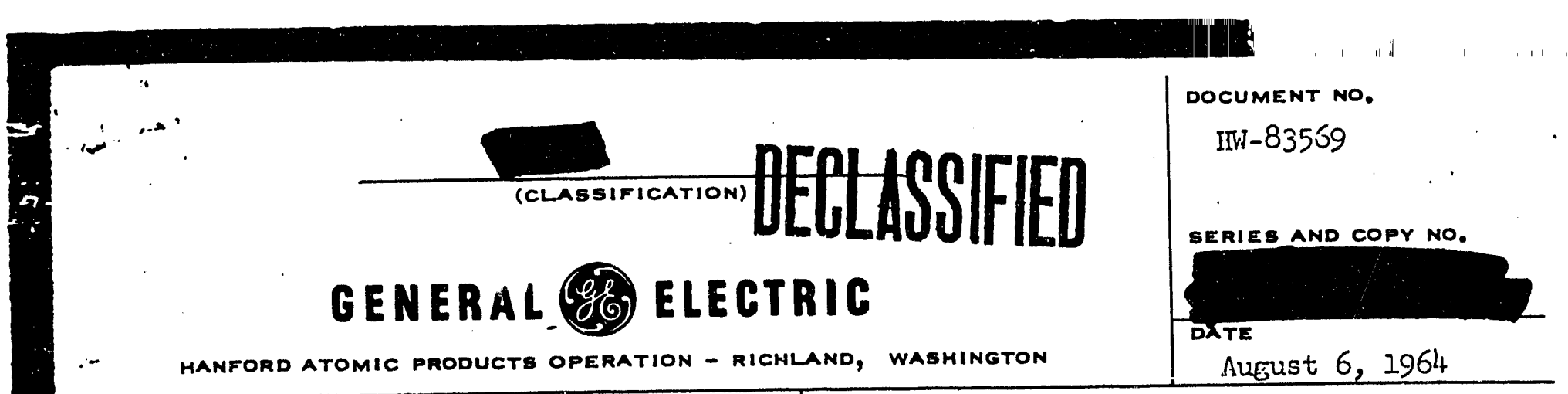

Aueust 6, 1964

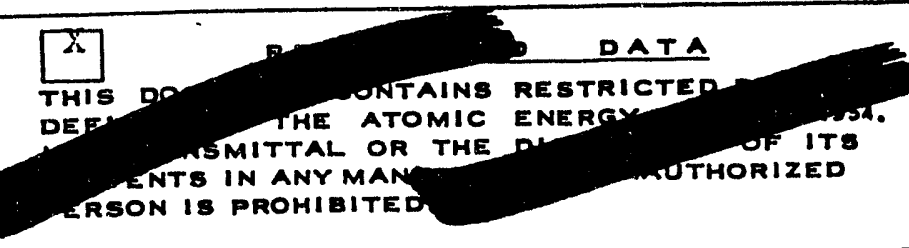

D OTHER OFFICIAL CLASSIFIED INFORMATION THIS MATERIAL CONTAINS INFORMATION AFFECTING THE NATIONAL DEFENSE OF THE UNITED STATEB WITHIN THE MEANING OF THE ESPIONAGE LAWB, TITLE 18, U.8.C., SECS. TO3 AND 794, THE TRANSMISBION OR REVELATION OF WHICH IN ANY MANNER TO AN UNAUTHORIZED PERBON IB PROHIBITED BY LAW.

\section{REACTOR PIIASE-OUT DISCHARGE PLATNIING}

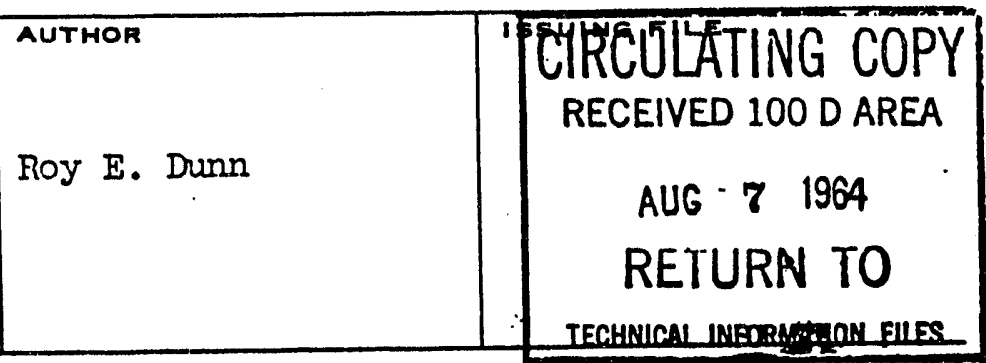
GUTHORIZED PERSON MM!

CCEs 8 APPROVED

THIS DOCUMENT TO IT. WHEN GUARD:-

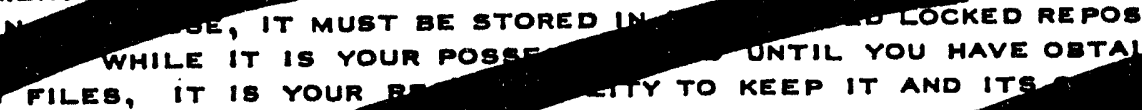

KEEP IT AND IT IZED PERSON. ITS TRANSM

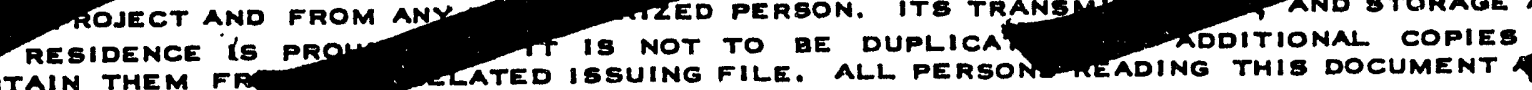
NED RECEIPT FP A WITHIN THE LIMI AND ETORAGE AT YOM MCE UIRED, AUE STED TO SIGN IN THE BP R PROVIDED BELOW.

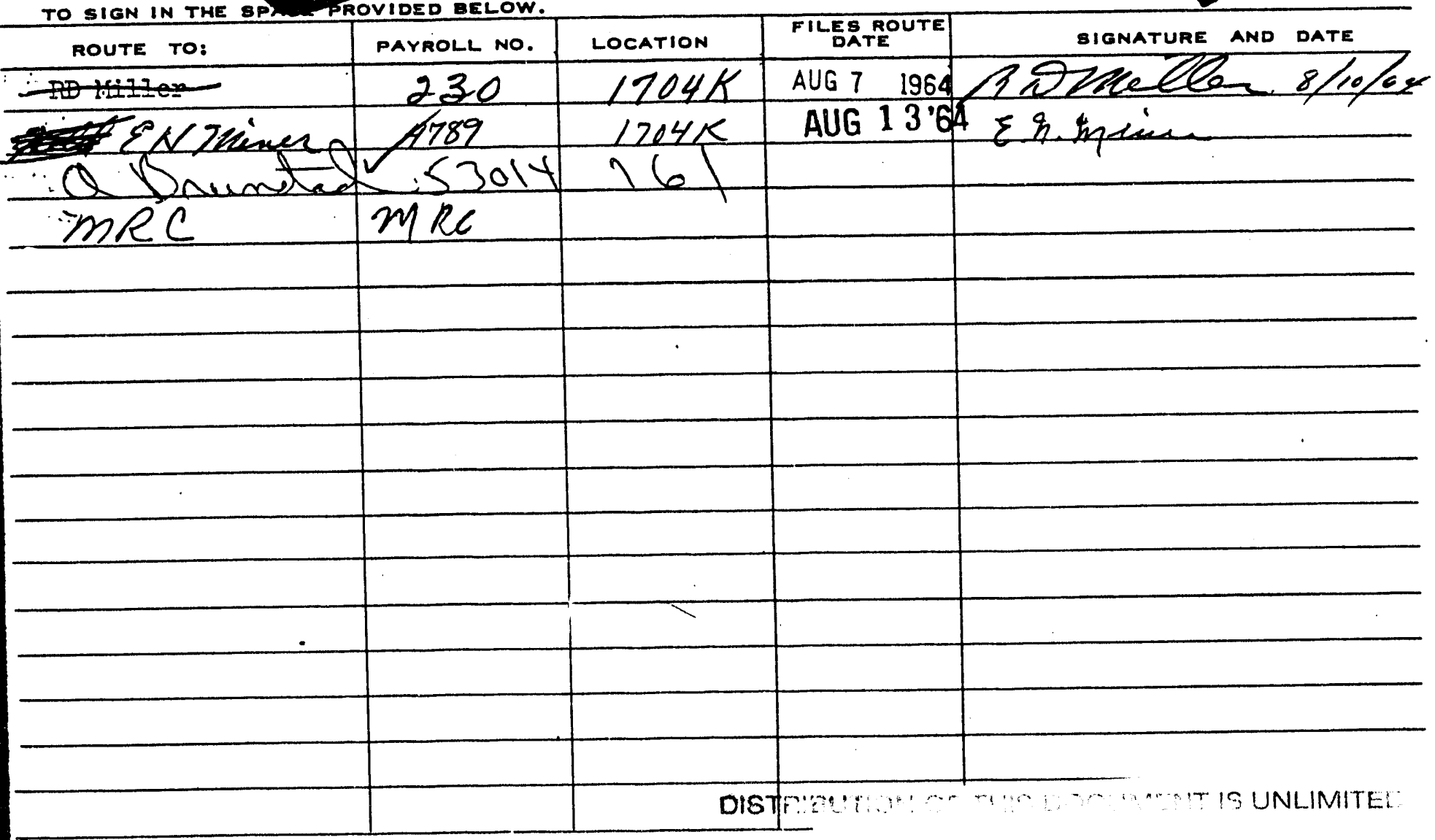

54-3000-340 (3-57) AEC.GE miCHLAND. WASH.

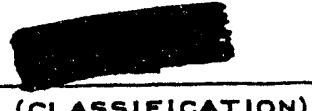




\section{GENERAL ELECTRIC}

RICHLAND, WASHINGTON
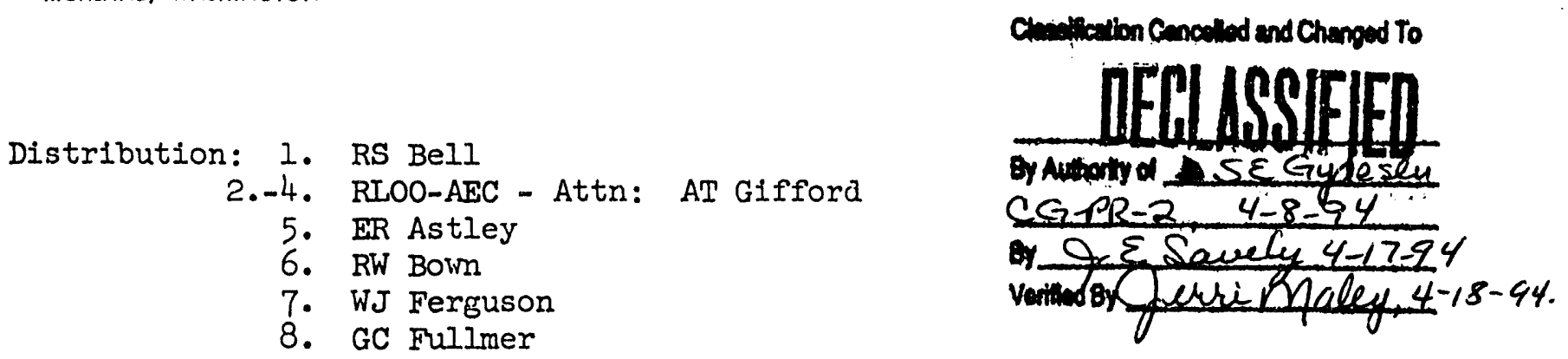

This document consists of
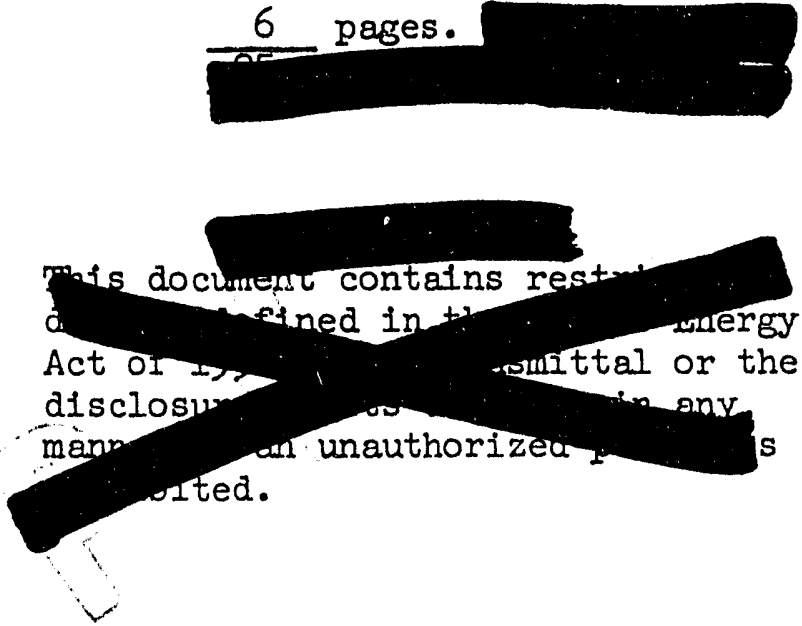

August 6, 1964

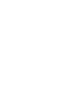

R. S. Bell, Manager Manufacturing Section

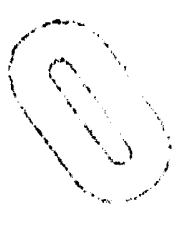




\section{GENERAL ELECTRIC}

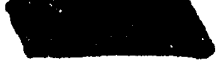

R. S. Bell
$-2-$
HW-83569

August 6,1964

This is accomplished by scheduling discharge of the alternate batches during the months preceding phase-out elther a little early or a little late causing their discharge dates to converge. A final date can then be found that will provide for discharge of the complete reactor with little loss in fuel utilization.

For fringe tubes, where the range of powers is fairly great, it is necessary to arrange tubes into power groups and to schedule each group independently. It has been found that, over a six-month period, fringe tubes can be forced into a pattern such that, at final discharge, all tubes will have a reasonable exposure without any being greatly overexposed.

Where the number of enriched tubes is small, it is necessary to plan reactor phase-out around natural material and to fit enriched material into the optimum natural schedule. Methodology is similar and unscheduled outages can be used to smooth out areas of incompatibility between the two fuel types.

A plan for phasing-out DR Reactor as of January 1, 1965, is shown in Table 1, illustrating how the techniques involved are used.

\section{DISCUSSION}

A Hanford production reactor is basically a large number of small production units (tubes). The power of each of these units is calculated from its coolant flow and temperature rise. Individual tube production is an integration of this power over time. The product accounting system is kept in balance by forcing the sum of all tube productions to equal total reactor production as reported daily by the Processing Operations. These tube power and production calculations are performed routinely on Production Sub-Section punched-card data processing equipment in the 2720 Building in 100-H Area.

\section{Tube Power Variability}

The individual tubes within any reactor involve a wide range of tube powers. This variety of tube powers together with the effects of the Variable Goal system of discharging, where target exposure is inversely proportional to tube power ${ }^{1}$, results in a wide range of reactor residence times for different charges. In theory, the highest power tube could be discharged six times during the period required for one cycle in the lowest power tube. In the normal situation, with good radial flux distribution, most central zone tubes operate within a fairly narrow power range $( \pm 10 \%$ of the average central zone tube power within each fuel type, i.e., enriched or natural uranium). Fringe tubes,

1- HW-59820, "Production Computation and Scheduling for Hanford Reactors," by W. G. Albert, dated March 16, 1959, (Confidential). 


\section{GENERAL ELETRIC}

HW-83569

R. S. Bell

$-3-$

August 6, 1964

i.e., tubes in the buckled zone, show considerably more power variation. In general, power is the lowest in the outer lattice, increasing with each succeeding inner lattice.

Normal Discharge Scheduling

Discharge planning for a production reactor involves determination of a date When a large number of central core tubes will be at the approved discharge exposure. ${ }^{2}$ Any fringe tubes near the target exposure are added in to make up the scheduled discharge. Current practice at some reactors is to discharge the entire central core at one outage (block discharge); at others, about half of the core is taken at each major discharge outage. In the latter case, there are two standard plans: 1) tubes for each outage are chosen at random depending on individual tube exposure, and 2) tubes are forced into an orderly discharge pattern such that alternate rows mature concurrently (semi-block or alternate row discharge is designed to improve charge-discharge and reactor flattening efficiency).

Core Phase-out Discharge Scheduling

In phasing-out a reactor the problem is to schedule discharging such that all tubes reach target exposure on or near the date designated for final reactor shutdown. The fuel discharged must contain acceptable product. Considering the extreme variability of tube powers discussed above, this is a formidaile task even at reactors where the core is discharged as a block. Random and alternate row situations present greater problems. This discussion deals with the latter case because its solution also covers the block discharge case. Furthermore, the first reactor to be phased-out (DR Reactor) is currently on an alternate row discharge plan.

For the central core the problem is to cause the two core batches involved to reach goal exposure as close together in time as is practical. These discharge dates will. not converge naturally because both sections operate at essentially the same power; hence, they should retain the same time relationship to one another.

Given a market for non-defense plutonium there would be no problem. When one core batch reached non-defense plutonium exposure, the other would have attained that exposure necessary to yield weapons grade plutonium. However, non-defense

2-HW-82522, "IPD Discharge Goal Exposure Plan (Revised 6-1-64)," by T. Prudich, dated May 28, 1964, (Secret).

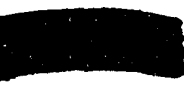




\section{GENERAL ELERTRIC}

IWW-83569

R. S. Bell

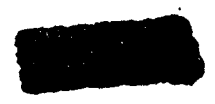

$-4-$
August 6, 1964

production has been stopped because current inventories of this product will cover the Commission's revised needs ${ }^{3}$ for some time. This plan should be investigated further before phase-out action is taken at $F$ and $H$ Reactors in case the market situation for this product changes.

Current planning for DR Reactor phase-out involves moving the discharge dates of the two core batches together somewhat by judicious use of fringe material to provide a blend product that is acceptable to the weapons program. Table 1 illustrates this point. Note that July and September DR discharges have lower core exposures than usual. The July material is discharged a few days early. Fuel charged in July is agaln discharged a few days earlier than usual during September, further reducing the elapsed time between this batch and the alternate core batch. In spite of this action, Table 1 shows that there is still considerable variation in the exposure of core material at final shutdown. One batch is well below target exposure ( $315 \mathrm{MWD} / \mathrm{Ton}$ ) while the other is slightly overexposed (615 MWD/Ton). The relatively small overexposure of core material is important in that it keeps slug rupture potential down.

Fringe Phase-out Discharge Scheduling

Fringe discharging presents a different type of problem. As discussed above, frinç tubes cover a broad power spectrum. In general, powers are low enough so that slug rupture potential can be largely ignored giving considerable latitude in planning discharge exposures. The problem is to discharge fringe tubes at the weapons product specification while generating the maximum amount of plutonium. The theoretical maximum yield occurs when all tubes are discharged at exactly the weapons product specification. The Greater the exposure variation, the less weapons grade plutonium is generated in a given number of tons of uranium. To state it another way, the greater the exposure variability, the lower must be the average exposure for the same plutonium quality.

It has been determined that about six months are required to cycle fringe tubes toward a single discharge with minimum exposure variability. Table 1 shows the plan worked out for DR Reactor fringe phase-out. Fringe tubes were divided into power groups with each group handled separately. In each group the attempt was made to equalize the exposure among the minimum number of cycles needed during the last six months of reactor operation. This is in line with the concept that minimizing the exposure variability maximizes the amount of

3-The most recent non-defense plutonium schedule is contained in a letter from A. T. Gifford to T. R. Clark, dated March 26, 1964.

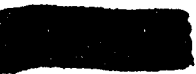




\section{GENERAL ELECTRIC}

HW -83569

R. S. Bell

$-5-$

August 6, 1964

product. In general, fringe metal is scheduled for discharge above the product specification with core (high powered) material coming out low in accordance with the Variable Goal principle.

Enriched Uranium Phase-out

The principles used in phasing-out enriched uranium are the same as those used for natural uranium discussed above. At DR Reactor the amount of enriched uranium is small compared to natural uranium. Therefore, the discharge of natural uranium must be controlling. Enriched uranium operates at higher poiver than does natural uranium charged in the same location. Target exposures are higher for economic reasons and because higher exposures are necessary to produce plutonium at the weapons specification. It is not surprising, then, that a different discharge schedule would be necessary to optimize enriched phase-out.

At DR Reactor the discharge of enriched uranium has been superimposed on the schedule for natural uranium discharging. Where this schedule does not rit (see September, Table I) an unscheduled outage is anticipated. Should no such outare occur, it will be necessary to determine whether or not an extra scheduled outage could be utilized effectively. If it could not, sluc rupture potential from overexposure of high-powered enriched fuel would be allowed to rise, increasing the probability of an unscheduled outage some time later than the optimum date.

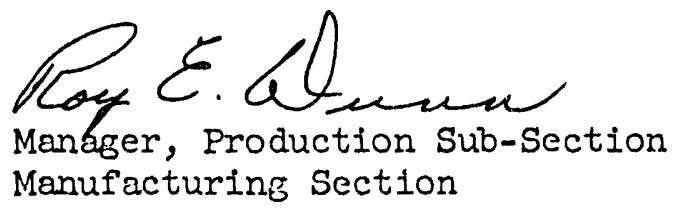

Roy E. Dunn:RWB:bm 
TABLE I

DR REACTOR PIUASE-OUT DISCHARGE PLAN

\begin{tabular}{|c|c|c|c|c|c|c|c|c|c|c|c|c|c|}
\hline \multirow{3}{*}{$\begin{array}{l}\text { Tube } \\
\text { Factor } \\
\text { Group }\end{array}$} & \multirow{3}{*}{$\begin{array}{l}\text { Reactor } \\
\text { Inventory } \\
\text { Tons }\end{array}$} & \multicolumn{12}{|c|}{ APPROX I HTE OUTAGE SCHEDUTLE } \\
\hline & & \multicolumn{2}{|c|}{ July 1} & \multicolumn{2}{|c|}{ Aus. 9} & \multicolumn{2}{|c|}{ Sept. 13} & \multicolumn{2}{|c|}{ Oct. 18} & \multicolumn{2}{|c|}{ INov. 23} & \multicolumn{2}{|c|}{$\operatorname{Jan} .1,1965$} \\
\hline & & Tons & MWD/Ton & Tons & 1.WD/Ton & Tons & MD/Ton & Tons & MWD/Ton & Tons & MID/Ton & Tons & Mrd $/$ Ton \\
\hline$>0.999$ & 102 & 54 & 550 & 53 & 570 & 49 & 560 & 53 & 600 & 49 & 600 & $\begin{array}{l}53 \\
49\end{array}$ & $\begin{array}{l}615 \\
315\end{array}$ \\
\hline$(50.899)$ & (23) & (10) & $(730)$ & (8) & (920) & $(15) *$ & $(850)$ & (8) & $(770)$ & - & - & $\begin{array}{r}(15) \\
(8)\end{array}$ & $\begin{array}{l}(860) \\
(770)\end{array}$ \\
\hline $0.900-0.999$ & 30 & 2 & 570 & 10 & 820 & 21 & 660 & 10 & 520 & - & - & $\begin{array}{l}21 \\
10\end{array}$ & $\begin{array}{l}810 \\
520\end{array}$ \\
\hline $0.700-0.899$ & 17 & 2 & 900 & - & - & 17 & 660 & - & - & - & - & 17 & 640 \\
\hline$(c .700-0.899)$ & (6) & (1) & (990) & (2) & $(1040)$ & (1) & $(720)$ & - & - & - & - & $\begin{array}{l}\text { (2) } \\
(1) \\
(2) \\
(1) \\
\end{array}$ & $\begin{array}{l}(1200) \\
(1050) \\
(1030) \\
(630)\end{array}$ \\
\hline $0.500-0.699$ & 16 & 9 . & 780 & 4 & 530 & - & - & - & - & - & - & $\begin{array}{l}3 \\
9 \\
4 \\
\end{array}$ & $\begin{array}{r}1000 \\
760 \\
620 \\
\end{array}$ \\
\hline$(0.500-0.699)$ & (4) & (1) & $(900)$ & (I) & $(1000)$ & - & - & - & - & - & - & $\begin{array}{l}(2) \\
(1) \\
(1)\end{array}$ & $\begin{array}{l}(1100) \\
(780) \\
(560) \\
\end{array}$ \\
\hline$<0.4 .99$ & 17 & 6 & 640 & - & - & - & - & - & - & - & - & $\frac{11}{6}$ & $\begin{array}{l}740 \\
510\end{array}$ \\
\hline$(<0.499)$ & (4) & (1) & $(890)$ & - & - & - & - & - & - & - & - & $\begin{array}{l}(3) \\
(1) \\
\end{array}$ & $\begin{array}{r}(1250) \\
(680) \\
\end{array}$ \\
\hline $\begin{array}{l}\text { Total } \\
\text { Iatural }\end{array}$ & 182 & 73 & 600 & 67 & 600 & 87 & 600 & 63 & 590 & 49 & 600 & 182 & 575 \\
\hline $\begin{array}{l}\text { Total } \\
\text { Enriched }\end{array}$ & (37) & (13) & $(870)$ & (11) & $(950)$ & $(16)$ & $(840)$ & (8) & $(770)$ & - & - & $(37)$ & $(900)$ \\
\hline $\begin{array}{l}\text { Reactor Input } \\
\text { KMJ from } 6-3\end{array}$ & & & & & $7 \cdot 5$ & & & & 2.5 & & 2.3 & & 7.4 \\
\hline
\end{tabular}

Values in parentheses concern enriched fuel, others are for natural fuel.

*To be discharged during an unscheduled outage in late September or early October, 

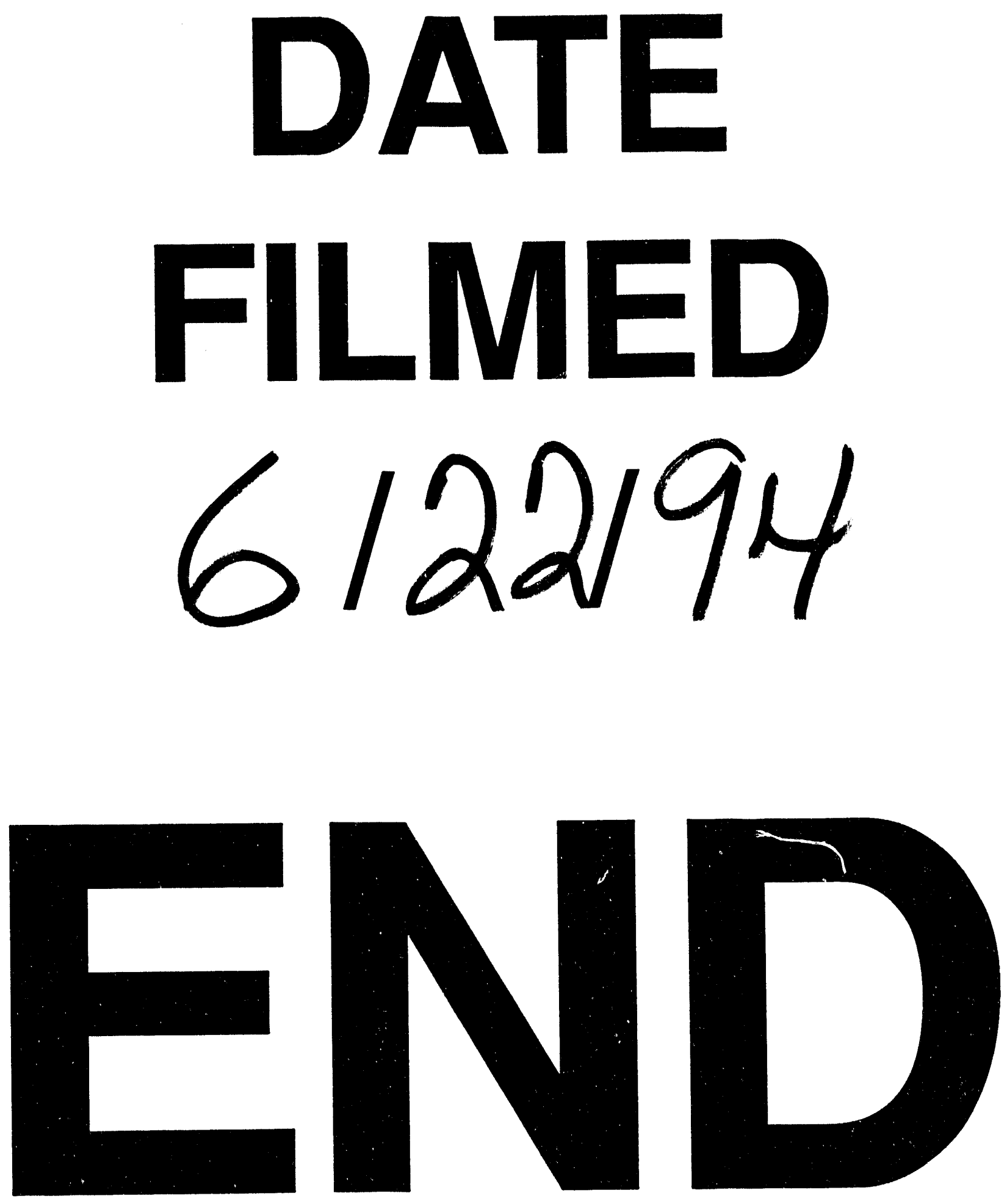


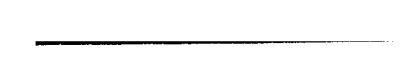

